\title{
Modifiye Hummers Yöntemi ile Elde Edilen Grafen Oksit Sentezleri İçin: Kısım 1, X Işını Difraksiyonu Analizi
}

\author{
Ömer Laçin ${ }^{1 *}$, Bünyamin Dönmez ${ }^{1}$ \\ ${ }^{1 *}$ Atatürk Üniversitesi, Mühendislik Fafültesi, Kimya Mühendisliği Bölümü, Erzurum, Türkiye (ORCID ID 0000-0002-5276-3056), olacin@atauni.edu.tr \\ ${ }^{1}$ Atatürk Üniversitesi, Mühendislik Fafültesi, Kimya Mühendisliği Bölümü, Erzurum, Türkiye (ORCID ID 0000-0002-7680-0755), bdonmez@atauni.edu.tr
}

(1st International Conference on Applied Engineering and Natural Sciences ICAENS 2021, November 1-3, 2021)

(DOI: $10.31590 /$ ejosat.)

ATIF/REFERENCE: Laçin, O. \& Dönmez, B. (2021). Modifiye Hummers Yöntemi ile Elde Edilen Grafen Oksit Sentezleri İçin: Kısım 1, X Işııı Difraksiyonu Analizi. Avrupa Bilim ve Teknoloji Dergisi, (28), 968-971.

$\ddot{O} \mathbf{z}$

Grafen Oksit, 2 boyutlu ve oksijen içeren fonksiyonel grupların yer aldığı karbon esaslı bir malzemedir. Son yıllarda grafen oksit esaslı malzemeler, bilim adamları tarafından çok büyük bir ilgi görmektedir. Grafen oksidin özellikleri; morfolojisine, doğasına ve reaksiyon şartlarına bağlı olmasından dolayı farklı şartlarda sentezlenen grafen oksidin özellikleri de farklı olmaktadır. Dolayısıyla literatüre giren her bir grafen oksit sentez çalışmasının önemli bir katkı sağlayabileceği düşünülmektedir. Bu çalışmada, Hummers yönteminde kullanılan sodyum nitrat konsantrasyonu değiştirilerek elde edilen sentezlerin başarılı bir şekilde grafen oksite dönüşüp dönüşmediği ve değişen yapısal özellikleri X ray Difraksiyonu analizi ile incelenmiştir. Analiz sonuçlarından hegzagonal grafit kristalinde;

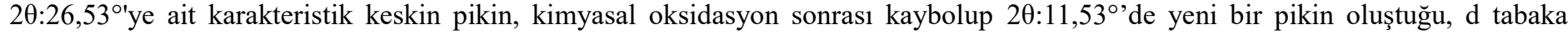
aralığının 0,34 nm'den 0,77 nm'ye genişlediği, kristal çapın 34,56 nm'den ortalama 7,22 nm'ye azaldığı ve tabaka sayısının 102'den 9'a düştüğü belirlenmiştir. Sonuç olarak bu şartlarda elde edilen sentezlerin, farklı özelliklere sahip grafen oksit örnekleri olduğu ve literatür ile uyum içerisinde oldukları söylenebilir.

Anahtar Kelimeler: Grafit, Grafen oksit, Hummers Yöntemi, Nanomalzeme, X-Ray Difraksiyonu

\section{For Graphene Oxide Synthesis Obtained by Modified Hummers Method: Part 1, X-Ray Diffraction Analysis}

\begin{abstract}
Graphene Oxide is a carbon-based material with 2-dimensional and oxygen-containing functional groups. In recent years, graphene oxide-based materials have attracted great interest by scientists. Properties of graphene oxide; Since it depends on its morphology, nature and reaction conditions, the properties of graphene oxide synthesized under different conditions are also different. Therefore, every graphene oxide synthesis study that enters the literature makes an important contribution. In this study, whether the syntheses obtained by changing the sodium nitrate concentration used in the Hummers method were successfully converted to graphene oxide and their changing structural properties were investigated by X-ray diffraction analysis. From the analysis results, it was determined that in the hexagonal graphite crystal; the characteristic sharp peak at $20: 26.53^{\circ}$ disappears after chemical oxidation and a new peak forms at $2 \theta: 11.53^{\circ}$, the $d$ layer spacing expands from $0.34 \mathrm{~nm}$ to $0.77 \mathrm{~nm}$, the crystal diameter decreases from $34.56 \mathrm{~nm}$ to an average of 7.22 $\mathrm{nm}$, and the number of layers decreases from an average of 102 to an average of 9 . Accordingly, it can be said that the syntheses obtained under these conditions are graphene oxide samples with different properties and are in agreement with the literature.
\end{abstract}

Keywords: Graphite, Graphene oxide, Hummers Method, Nanomaterial, X-Ray Diffraction 


\section{Giriş}

Karbonun yaygın allotroplarından olan grafit kristali, altıgen şeklinde dizilen karbon atomlarının birbirine güçlü kovalent bağları ve düzlemler arasının ise zayıf Van Der Walls bağlarıyla bağlanarak üç boyutlu bir yapı sergiler. Van Der Walls bağlarının zayıf olmaları sebebiyle tabakalar birbirlerinden çok kolay bir şekilde ayrılabilirler. Grafitin düşük maliyetli, kolay elde edilebilirliği, grafen oksit ile onun türevlerinden oluşan kompozit malzemelere ve grafene kolaylıkla dönüştürülebilmesi nedeniyle son y1llarda çok büyük bir ilgi görmektedir [1-2].

Grafen Oksit (GO), 2 boyutlu, oksijen içeren fonksiyonel grupların olduğu karbon esaslı bir malzeme olup grafitin oksidasyonundan grafit oksite ve sonra çok sayıdaki tabakaların ayrışmasıyla grafen oksite kolayca dönüşebilmektedir. GO, yapısındaki oksijen içeren fonksiyonel gruplarının, $\mathrm{sp}^{2}$ hibritleşmesi yapan karbon atomlarının $\mathrm{sp}^{3}$ hibritleşmesi yapan karbon atomlarına oranının kontrol edilebilir olması, ayarlanabilir elektronik ve optik özelliklere sahip olmasıyla birlikte hidrofiliklik, ve suda çok iyi disperse olabilmesi nedeniyle; enerji depolamadan biyomedikale, kaplama teknolojisinden savunma sanayiine kadar geniş bir uygulama alanı bulmaktadır. Sentez aşamalarında, hem reaktanlar hem de yan ürünlerin tehlikeli kimyasallar içermesinden dolayı, bunları minimize etme adına son yıllarda grafitten grafen oksit eldesi üzerine oldukça fazla çalışma yapılmaktadır [3-8].

Grafen oksitin özellikleri; morfolojisine, doğasına ve reaksiyon şartlarına bağlı olduğundan, farklı şartlarda sentezlenen grafen oksitin özellikleri de farklı olmaktadır. Dolayısıyla sentezlenen her grafen oksit literatüre önemli bir katk1 sağlamaktadır [9].

Grafen Oksit üretmek için yapılan araştırmalarda en uygun yöntemin; üretim kolaylığı, sentez süresinin kısa oluşu, maliyetinin düşük ve yan ürünlerinin diğer yöntemlere göre daha az toksik olamsından dolayı, Hummers yöntemi [10] olduğu belirlenmiştir. $\mathrm{Bu}$ yöntemde grafitin, $\mathrm{KMnO}_{4}$, konsantre $\mathrm{H}_{2} \mathrm{SO}_{4}$ ve $\mathrm{NaNO}_{3}$ karışımı ile reaksiyona sokulmasıyla oksidasyon gerçekleştirilmiştir. Permanganat yaygın olarak kullanılan bir oksidan olmasına rağmen gerçek aktif tür, aromatik yapılar üzerindeki doymamış alifatik çift bağları seçici olarak oksitleyebilen $\mathrm{Mn}_{2} \mathrm{O}_{7}$ 'dir [11]. GO üretim yöntemlerinin ortak dezavantajları toksik ve tehlikeli kimyasalların kullanılması ve üretim prosesi esnasında bir takım zehirli gazların ortaya çıkmasıdır. Hummers yönteminin avantajları; patlayıcı özelliğe sahip $\mathrm{ClO}_{2}$ yerine $\mathrm{KMnO}_{4}$ gibi kuvvetli bir oksitleyici ajan kullanımı ve beraberinde reaksiyon süresinin kısalması ve dumanlı asit buharı oluşturan nitrik asit yerine sodyum nitrat kullanılmasıdır. $\mathrm{Bu}$ yöntemin dezavantajları ise; $\mathrm{NO}_{2}$ ve $\mathrm{N}_{2} \mathrm{O}_{4}$ gibi toksik gazların oluşması, $\mathrm{KMnO}_{4}$ 'n $95{ }^{\circ} \mathrm{C}$ 'nin üzerinde patlama riski ve kristal kafese hapsolan sulu çözeltideki $\mathrm{Na}^{+}$ve $\mathrm{NO}_{3}{ }^{-}$iyonlarının uzaklaştırılma zorluğudur [12].
$\mathrm{Bu}$ yüzden Hummers yöntemi, bazı çalışmalarda modifiye edilerek bu dezavantajları azaltma yolları araştırılmıştır. $\mathrm{Bu}$ çalışmaların bazılarında, reaksiyon şartları değiştirilmiş, $\mathrm{KMnO}_{4}$ yerine $\mathrm{K}_{2} \mathrm{FeO}_{4}$ kullanılmış, $\mathrm{NaNO}_{3}$ yerine ise konsantre asit miktarı artırılmış veya $\mathrm{H}_{2} \mathrm{SO}_{4}$ ile birlikte $\mathrm{H}_{3} \mathrm{PO}_{4}$ kullanılmıştır [13].

$\mathrm{Bu}$ çalışmada, Hummers yöntemindeki $\mathrm{NaNO}_{3}$ konsantrasyonu değiştirilerek elde edilen ürünlerin uygun bir şekilde grafen oksite dönüşüp dönüşmediği ve değişen yapısal özelliklerinin, X-1şını difraksiyon (XRD) analizi ile incelenmesi amaçlanmıştır.

\section{Materyal ve Metot}

\subsection{Kullanılan Kimyasallar}

Deneysel çalışmada kullanılan kimyasallar; grafit ince toz (merck 325 meş), sodyum nitrat (merck), \%98'lik sülfürik asit (merck), potasyum permanganat (merck), ultra deiyonize su, \%30'luk hidrojen peroksit (merck) ve \%37 'lik hidroklorik asit (fluka).

\subsection{Deney için Kullanılan Materyaller}

Ultrasonik banyo 150w (çalışkan lab.), 1sıtıcılı manyetik karıştırıcı (1ka yellowline msh basic), pH metre (mettler toledo), santifürüj cihazı, etüv, termometre, $250 \mathrm{ml}$ 'lik cam reaktör ve çeker ocak.

\subsection{Modifiye Hummers Yöntemi ile Grafen Oksit Sentezleri}

Bu çalışmada, ara katmanlarda safsızlık olarak bulunan azot türevli yapıların oranının azaltılması veya tamamen giderilebilmesi için, Hummers yönteminde kullanılan sodyum nitrat konsantrasyonu, $0-1$ g. $\mathrm{NaNO}_{3} .23 \mathrm{~mL}^{-1}$ asit aralı̆̆ında değiştirilerek dört farklı GO sentezi elde edilmiştir. Elde edilen 4 GO numunesine $\mathrm{NaNO}_{3}$ '’n artan konsantrasyonuna göre sırasıyla, GO-Na0; GO-Na0,25; GO-Na0,50 ve GO-Na1 kodlar1 verilmiştir.

Bütün deneylerde toplam reaksiyon süresi, ortalama 4 saate düşürülmüştür. $\mathrm{Az}$ tabakalı GO'i sentezleyebilmek için ultrasonifikasyonla muamele yoluna gidilmiştir.

\subsection{Deneysel Sistem}

Grafen oksit sentezi için deneysel akış şeması Şekil 1'de verilmiştir. Reaksiyon boyunca uygulanan karıştırma hızı, homojen bir süspansiyonun elde edildiği $500 \mathrm{rpm}$ olarak belirlenmiştir. Reaksiyonun gerçekleşeceği $250 \mathrm{~mL}$ 'lik reaktöre, $1 \mathrm{~g}$ grafit tozu, 0-1g aralığında değişen $\mathrm{NaNO}_{3}$ ve $23 \mathrm{~mL} \mathrm{H}_{2} \mathrm{SO}_{4}$ ilave edilerek $30 \mathrm{dk}$ karıştırıldıktan sonra literatürdeki diğer modifiye Hummers yöntemlerinden farklı olarak, 40 dakika boyunca $-15{ }^{\circ} \mathrm{C}$ 'de dondurucuda bekletilmiştir. Numune buz banyosunda $0{ }^{\circ} \mathrm{C}^{\prime}$ ye getirilmiş ve karışıma patlama riskini minimize etmek için yaklaşık 1 saat süre içerisinde kademeli olarak ve sıcaklık $5{ }^{\circ} \mathrm{C}$ yi geçmeyecek şekilde kontrollü bir 
karıştırmayla 3 g $\mathrm{KMnO}_{4}$ ilave edilerek Eşitlik (1 ve 2) oksidasyon reaksiyonları gerçekleştirilmiştir.

$$
\begin{aligned}
& \mathrm{KMnO}_{4}+3 \mathrm{H}_{2} \mathrm{SO}_{4} \rightarrow K^{+}+\mathrm{MnO}_{3}^{+}+\mathrm{H}_{3} \mathrm{O}+3 \mathrm{HSO}_{4}^{-} \\
& \mathrm{MnO}_{3}^{+}+\mathrm{MnO}_{4}^{-} \rightarrow \mathrm{Mn}_{2} \mathrm{O}_{7}
\end{aligned}
$$

Reaksiyonda oluşan $\mathrm{HSO}_{4}^{-}$iyonları grafit bazal düzlemine saldırırken, $\mathrm{Na}^{+}$iyonları grafit tabakaları arasına girer ve burada d aralığını genişletir [14].

Reaksiyon sonunda elde edilen koyu yeşil renkli grafit oksidi, mekanik olarak grafen okside dönüştürmek amacıyla, sıcaklık 35 ${ }^{\circ} \mathrm{C}$ 'ye ayarlanıp $50{ }^{\circ} \mathrm{C}$ 'yi geçmeyecek şekilde numune 2 saat boyunca karıştırılmıştır. Süre sonunda açık kahverenkli karışımın sıcaklığ1 $98{ }^{\circ} \mathrm{C}^{\prime}$ ye yükseltilip $46 \mathrm{~mL}$ ultra saf su, kontrollü bir biçimde ilave edilmiştir. Bu esnada çıkan gazların renginin mor olduğu gözlenmiştir. $98{ }^{\circ} \mathrm{C}$ 'de tutulan nihai karışım $15 \mathrm{dk}$ boyunca karıştırıldıktan sonra rengin koyu kahverengiye döndüğü gözlenmiştir. Daha sonra, $140 \mathrm{~mL}$ ultra saf su ve $8 \mathrm{~mL} \mathrm{H}_{2} \mathrm{O}_{2}$ ilavesiyle renk sarıya dönüşmüş ve $\mathrm{KMnO}_{4}$ fazlası Eşitlik (3)' de gösterildiği gibi suda çözünen mangan sülfat tuzuna dönüştürülmüştür.

$2 \mathrm{KMnO}_{4}+3 \mathrm{H}_{2} \mathrm{SO}_{4}+3 \mathrm{H}_{2} \mathrm{O}_{2} \rightarrow 2 \mathrm{MnSO}_{4}+2 \mathrm{~K}_{2} \mathrm{SO}_{4}+8 \mathrm{H}_{2} \mathrm{O}+$ $5 \mathrm{O}_{2}$

Elde edilen son karışım 1 gün boyunca oda sıcaklığında bekletildikten sonra süzülmüştür. Katı numune, bünyesindeki metal iyonlarını gidermek için \%10'luk $\mathrm{HCl}$ ile ve sonrasında ortamdaki reaksiyona girmeyen asit fazlasını gidermek için saf su ile pH 7 olana kadar birkaç kez yıkanmıştır. Karışım etüvde 4 saat $60{ }^{\circ} \mathrm{C}$ 'de kurutulduktan sonra saf su ilave edilerek elde edilen grafen oksit süspansiyonu 2 saat boyunca sonikasyona (güç: 150 W ve frekans: $33 \mathrm{KHz}$ ) tabi tutulmuş ve $5 \mathrm{dk}$ boyunca 3000 dev.dk ${ }^{-1}$ hız ile santifürüj edilerek çözeltisinden ayrılmıştır. Son olarak, katı numune $60{ }^{\circ} \mathrm{C}$ 'de etüvde 1 gün boyunca kurutularak grafen oksit sentezi gerçekleştirilmiştir.

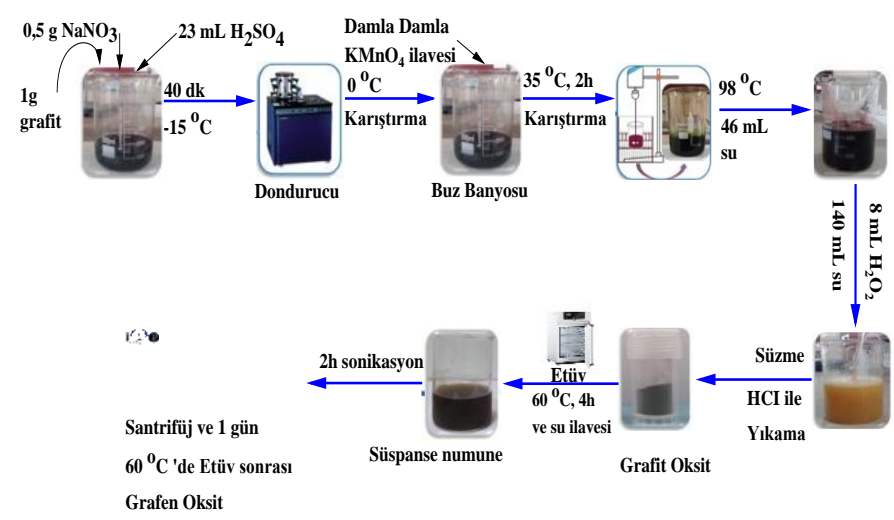

Şekil 1. Grafen Oksit Sentezi için Deneysel Akış Şeması

\subsection{Ray Difraksiyonu Analizi}

XRD analizi, örneklerde karekteristik pikleri, grafit tabakalar ile kristalin özellikler arasındaki ara katman aralığını, kristal çaplarını ve tabaka sayılarını tahmin etmede kullanılır. Bragg denklemi ile (Eşitlik 4) d aralığ 1 ve Schererr denklemi ile (Eşitlik e-ISSN: 2148-2683
5) kristal çapı belirlenir. Ayrıca, Grafit ve ortalama GO tabaka sayısı $\left(t_{n}\right)$ ise, kristal çapının d aralığına oranı ile hesaplanır.

$\mathrm{n} \lambda=2 \mathrm{~d} \sin \theta$

$D=\frac{b \lambda}{\beta \cos (\theta)}$

Burada $\lambda$, 1şının dalga boyu; $d$, kafes düzlemleri arasındaki boşluk; $\theta$; X ışınının yaptığı açı, n; tamsayı olan yansıma sayısı, $\mathrm{b}$; şekil faktörü ve $\beta$; maksimum pikin yarı genişliği (FWHM)'nin radyan cinsinden değeridir.

XRD çalışmaları, X-ışını kaynağı olarak $\mathrm{Cu} \quad \mathrm{K} \alpha$ radyasyonuna sahip bir PANalytical Empyrean difraktometresi kullanılarak 0.0001 minimum adım boyutu ile 20: 5-90 aralığında taranarak yapılmıştır.

\section{Araştırma Sonuçları ve Tartışma}

Grafit ve sentezlenen GO'ların XRD modelleri Şekil 2'de grafik edilmiş olup buradaki verilerden faydalanarak hesaplanan $\mathrm{d}$ aralığı, kristal çapı ve tabaka sayıları Tablo 1'de verilmiştir.

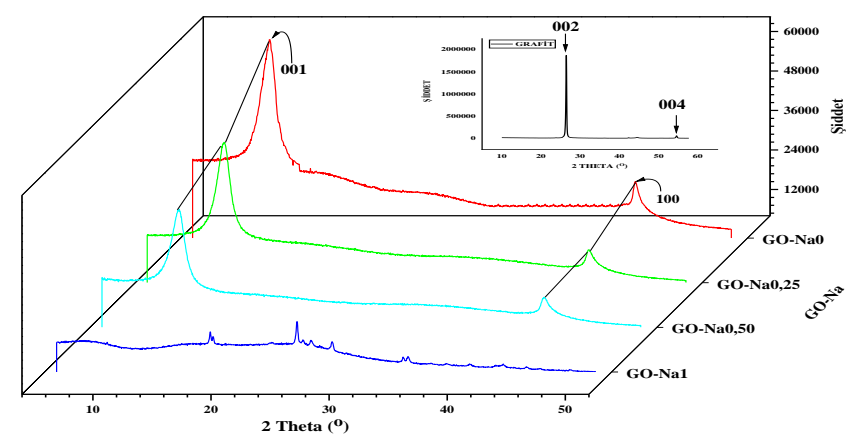

Şekil 2. Grafit ve GO-Na'un XRD Modelleri

\begin{tabular}{|c|c|c|c|c|c|c|c|}
\hline Numune & hkl & $2 \theta\left({ }^{\circ}\right)$ & $\begin{array}{l}\text { Pik } \\
\text { Alanı } \\
(\%)\end{array}$ & $\begin{array}{l}d \\
(\mathrm{~nm})\end{array}$ & $\begin{array}{l}\text { FWHM } \\
\left({ }^{\circ}\right)\end{array}$ & $\begin{array}{l}\mathbf{D}_{001} \\
(\mathbf{n m})\end{array}$ & $t_{n}$ \\
\hline \multirow[t]{2}{*}{ Grafit } & 002 & 26,53 & 97 & 0,34 & 0,2362 & \multirow[t]{2}{*}{34,56} & \multirow[t]{2}{*}{102} \\
\hline & 004 & 54,64 & 3 & 0,17 & 0,3937 & & \\
\hline \multirow[t]{2}{*}{ GO-Na0 } & 001 & 11,53 & 75 & 0,77 & 1,0236 & \multirow[t]{2}{*}{7,80} & \multirow[t]{2}{*}{10} \\
\hline & 100 & 42,51 & 25 & 0,21 & 0,7874 & & \\
\hline \multirow{2}{*}{$\begin{array}{l}\text { GO- } \\
\text { Na0,25 }\end{array}$} & 001 & 11,53 & 77 & 0,77 & 1,2075 & \multirow[t]{2}{*}{6,61} & \multirow[t]{2}{*}{9} \\
\hline & 100 & 42,38 & 23 & 0,21 & 0,7350 & & \\
\hline \multirow{2}{*}{$\begin{array}{l}\text { GO- } \\
\text { Na0,50 }\end{array}$} & 001 & 11,53 & 75 & 0,77 & 1,1025 & \multirow[t]{2}{*}{7,24} & \multirow[t]{2}{*}{9} \\
\hline & 100 & 42,45 & 25 & 0,21 & 0,8400 & & \\
\hline \multirow[t]{2}{*}{ GO-Na1 } & 001 & 18,25 & - & 0,49 & 0,4725 & \multirow[t]{2}{*}{17,03} & \multirow[t]{2}{*}{35} \\
\hline & 100 & - & - & - & 2,5200 & & \\
\hline
\end{tabular}

Tablo 1. Grafit ve GO-Na Örneklerinin d, D ve tn değerleri.

\section{Sonuç}

Şekil 2 ve Tablo 1'den faydalanarak aşağıdaki sonuçlar elde edilmiştir:

XRD desenlerinden, grafit ve kimyasal oksidasyon sonras1 sentezlenen GO-Na örnekleri incelendiğinde, grafit yapısının oksidasyon işlemlerinden sonra önemli derecede değişikliğe uğradığı gözlenmiştir. 
Hegzagonal grafit kristalinde, 0,34 nm'lik bir ara tabaka mesafesine karşılık gelen 20:26,53 ${ }^{\circ}$ de keskin bir 002 (\%97 alanlı) piki ve $0,17 \mathrm{~nm}$ 'lik bir ara tabaka mesafesine karşılık gelen 20:54,64 'de ise zayıf 004 (\%3 alanlı) piki gözlenmiştir. Bu değerlerin literatürde geçen çalışmalara ait grafit piklerinin değerleri ile uyum içerisinde oldukları belirlenmiştir [15-17].

GO kristallerinde (GO-Na1 hariç), 0,77 nm'lik ara tabaka mesafesine karş1lık gelen $2 \theta: 11,53^{\circ}$ de keskin bir 001 (yaklaşık $\% 75$ alanlı) piki ve $0,21 \mathrm{~nm}$ 'lik ara tabaka mesafesine karşılık

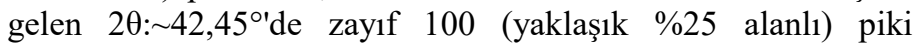
gözlenmiştir.

Grafitteki 20:26,53 ${ }^{\circ}$ de karakteristik keskin pikin, kimyasal oksidasyon sonrası kaybolması ve $2 \theta: 11,53^{\circ}$ 'de GO için yeni bir pikin oluşması ve d tabaka aralığının $0,34 \mathrm{~nm}$ 'den $0,77 \mathrm{~nm}$ 'ye genişlemesi (\%126'lık bir artış), sentezlerin başarılı bir şekilde gerçekleştiğininin göstergesidir (GO-Nal hariç). Çünkü, GO’ya ait karakteristik pikin literatür değeri yaklaş1k $2 \theta \sim 11^{\circ}$ 'dir, bu

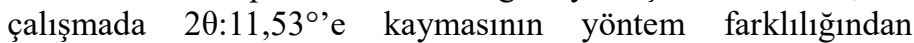
kaynaklandığg düşünülmekte- dir [18-19]. GO'nun karakteristik d aralığ 1 , oksidasyon derecesine bağlı olarak genellikle 0.7 ile 0.8 $\mathrm{nm}$ arasında değişmek- tedir [20].

Dolayısıyla, oksidasyondan sonra grafit bazal düzleminin merkezine ve kenarlarına oksijen içeren fonksiyonel grupların girmesi interkalasyonu ve bu grupların mevcut suyu absorplaması sonucu ara tabaka mesafesinin genişlemesiyle ortaya çıkan bu yeni yapıların literatürdeki GO sentezleriyle uyum içerisinde oldukları söylenebilir [15-17].

Grafitte 20:26,53 ' $\mathrm{de}$ keskin karakteristik 002 düzlemine karşılık gelen pike göre, kristal çapı yaklaşık 34,56 nm ve tabaka sayıs1 102 olarak hesaplanmıştır. Oksidas- yondan sonra sentezlenen GO örneklerinde ise $2 \theta: 11,53^{\circ}$ de karakteristik 001 düzlemine karşılık gelen pike göre kristal boyutu ortalama 7,22 $\mathrm{nm}$ ve tabaka sayısı ortalama 9'a düşmüştür. $\mathrm{Bu}$ sonuç, GO-Na1 hariç diğer sentezlerin başarılı bir şekilde gerçekleştiğini ortaya koyabilir.

Yapılan deneysel çalışma sonuçları 1şığında, verilen şartlarda elde edilen sentezlerin, farklı özelliklere sahip grafen oksit örnekleri oldukları ve literatür ile de uyum içerisinde oldukları söylenebilir.

\section{Teşekkür}

Bu çalışma, Atatürk Üniversitesi BAPSİS Birimi tarafından Temel Araştırma Projesi olarak desteklenmiştir.

\section{Kaynakça}

[1] Moosa, A., and Abed, M. (2021). Graphene preparation and grapfite exfoliation. Turkish journal of Chemistry, 45(3),493-519.

[2] Dresselhaus, G., Dresselhaus, M. S., \& Saito, R. (1998). Physical properties of carbon nanotubes. World scientific.

[3] Brisebois, P. P., \& Siaj, M. (2020). Harvesting graphene oxide-years 1859 to 2019: a review of its structure, synthesis, properties and exfoliation. Journal of Materials Chemistry C, 8(5), 1517-1547.

[4] Paulchamy, B., Arthi, G., \& Lignesh, B. D. (2015). A simple approach to stepwise synthesis of graphene oxide nanomaterial. J Nanomed Nanotechnol, 6(1), 1.

[5] Tiyek, İ., Dönmez, U., Yıldırım, B., Alma, M. H., Ersoy, M. S., \& Karataş, Ş. (2016). Kimyasal yöntem ile indirgenmiş grafen oksit sentezi ve karakterizasyonu. Sakarya University Journal of Science, 20(2), 349-357.

[6] Huang, X., Qi, X., Boey, F., \& Zhang, H. (2012). Graphenebased composites. Chemical Society Reviews, 41(2), 666686.

[7] Sun, L., \& Fugetsu, B. (2013). Mass production of graphene oxide from expanded graphite. Materials Letters, 109, $207-$ 210.

[8] Chen, J., Yao, B., Li, C., \& Shi, G. (2013). An improved Hummers method for eco-friendly synthesis of graphene oxide. Carbon, 64, 225-229.

[9] Shamaila, S., Sajjad, A. K. L., \& Iqbal, A. (2016). Modifications in development of graphene oxide synthetic routes. Chemical Engineering Journal, 294, 458-477.

[10] Hummers Jr, W. S., \& Offeman, R. E. (1958). Preparation of graphitic oxide. Journal of the american chemical society, 80(6), 1339-1339.

[11] Dreyer, D. R., Park, S., Bielawski, C. W., \& Ruoff, R. S. (2010). The chemistry of graphene oxide. Chemical society reviews, 39(1), 228-240.

[12] Lavin-Lopez, M. D. P., Romero, A., Garrido, J., SanchezSilva, L., \& Valverde, J. L. (2016). Influence of different improved hummers method modifications on the characteristics of graphite oxide in order to make a more easily scalable method. Industrial \& Engineering Chemistry Research, 55(50), 12836-12847.

[13] Marcano, D. C., Kosynkin, D. V., Berlin, J. M., Sinitskii, A., Sun, Z., Slesarev, A., ... \& Tour, J. M. (2010). Improved synthesis of graphene oxide. ACS nano, 4(8), 4806-4814.

[14] Peng, L., Xu, Z., Liu, Z., Wei, Y., Sun, H., Li, Z., ... \& Gao, C. (2015). An iron-based green approach to 1 -h production of single-layer graphene oxide. Nature communications, 6(1), 1-9.

[15] Zhao, J., Liu, L., \& Li, F. (2015). Graphene oxide: physics and applications (Vol. 1, p. 161). London, UK:: Springer.

[16] Siburian, R., Sihotang, H., Raja, S. L., Supeno, M., \& Simanjuntak, C. (2018). New route to synthesize of graphene nano sheets. Oriental Journal of Chemistry, 34(1), 182.

[17] Divya, K. S., Chandran, A., Reethu, V. N., \& Mathew, S. (2018). Enhanced photocatalytic performance of RGO/Ag nanocomposites produced via a facile microwave irradiation for the degradation of Rhodamine $\mathrm{B}$ in aqueous solution. Applied Surface Science, 444, 811-818.

[18] ullah Khan, F., Mahmood, S., Ahmad, Z., Mahmood, T., \& Nizami, Z. A. Graphene oxide synthesis by facile method and its characterization.

[19] ZFan, Z., Wang, K., Wei, T., Yan, J., Song, L., \& Shao, B. (2010). An environmentally friendly and efficient route for the reduction of graphene oxide by aluminum powder. Carbon, 48(5), 1686-1689.

[20] Huang, H. H., De Silva, K. K. H., Kumara, G. R. A., \& Yoshimura, M. (2018). Structural evolution of hydrothermally derived reduced graphene oxide. Scientific reports, 8(1), 1-9. 